\title{
On the Administrative Level of Chinese Colleges and Universities
}

\author{
Zu-qiang LIANG \\ Department of Sport and Physical Education, Shenzhen Polytechnic, Shenzhen, \\ China.
}

Keywords: Colleges and universities, Administrative level, Relations between university and government.

\begin{abstract}
From the perspective of origin, there was no administrative level in colleges and universities. From the perspective of function performance, the administrative level is not indispensable to colleges and universities. Facts have proved that the administrative level is the "arch-criminal" of administrativization of colleges and universities. Therefore, there should not be the administrative level in colleges and universities. However, colleges and universities are looking for their own level in the development scale, function orientation, preference of science and techniques, nature of school, and other aspects, which can be described as inundation of level complex. What colleges and universities really need is the talent level - a master level teachers team.
\end{abstract}

\section{Introduction}

Colleges and universities are the general designation of universities, professional schools and technical colleges. The administrative level of colleges and universities has been criticized by people. However, in China, there are still plenty of people who hold the concept of "cancelling the university administrative level will belittle education, resulting in failure of 'butt joint' between university and society" [1]. Do the colleges and universities really need administrative level?

\section{There Was No Administrative Level in Colleges and Universities Originally.}

Since the birth of colleges and universities, a system has been formed. The medieval universities in Europe were not attached to any other organization, even in tough times, they at most, in the cracks of religious forces and secular regime, turned things around and survived, but had never become a vassal of any parties. How can it be said that there was "level" and "administrative level" in this "free state" of colleges and universities? In contrast, the formation of autonomy tradition, even until today, had become a "shield" of colleges and universities, as a kind of cultural capital in the game with the government. After the establishment of the national state, the government gradually gained control of colleges and universities. Colleges and universities gradually stepped into the social center from the ivory tower and became the "gas station" and "service station" to promote social and economic development, however, they existed only as public institutions to serve for the society, and were not given any administrative level. Modern university's father, Wilhelm von Humboldt then the Prussian Minister of Education, founded University of Berlin and became its first president which, however, did not represent the administrative level, namely ministerial rank of the world's first modern university, the successor therefore didn't inherit the administrative level. Similarly, it was unprecedented that colleges and universities were given administrative level in the history of the development of 
Chinese colleges and universities. Before 1949, none of the national universities, such as Peking University, Tsinghua University, etc., had administrative level.

Indeed, with the establishment of modern universities, the scale of universities were continuously expanding until the emergence of "huge university". It was until the early 20th century, the individual officers headed by the presidents were not able to complete the increasingly complex management tasks of the universities, thus management personnel were separated from the teachers team and management work began to be served by full-time management experts. It was also true that colleges and universities at that time, on the base of the discipline differentiation, scale expansion and division of labor, began to transform the organization form to bureaucratic form with relatively higher structure level [2]. However, they had nothing to do with administrative level.

\section{The Administrative Level Is Not Indispensable to Colleges and Universities.}

The nature of colleges and universities mainly presents as educational, academic, comprehensive, creative, social, service, etc.[3]. The general functions of colleges and universities include personnel training, scientific research and social services. However, the specific connotation of nature and functions in colleges and universities are not invariable, it will continuously develop and reform with the constantly changing of the certain social and political system and economic system. Since the rise of the nation state, the evolution process of the relations between colleges and universities and the government has been gradually moving towards cooperation from autonomy and controlled relations.[4] The government has become the biggest funder of funding colleges and universities. And, "who funded who set the tone" is the golden rule in the field of colleges and universities [5]. Therefore, colleges and universities in the certain degree is required to "obey the orders" from the government to assume the task to provide the community quasi-public products. Accordingly, in the sequence of government management, colleges and universities are attributed to the service sector to provide public goods to the society. However, in the organization category, they are classified as "public welfare organizations" and "non governmental organizations" (NGO). Naturally, this kind of organizations independent from the government have no administrative level, nor do they need any administrative level. In fact, the practice of the excellent universities in western developed countries has also proved that it won't prevent the perfect fulfillment of their various functions without administrative level. In the United States, at least top 10 universities are private universities. In UK, the public colleges and universities are funded by the University Grants Committee according to the quality of their school which is absolutely irrelevant to any level.

After the founding of new China, China has pursued the public ownership based socio-economic management system and has established a higher concentration of the centrally planned economic system. Colleges and universities, as public institutions, have achieved integration with government and have been treated as a part of "superstructure"[6], which to a certain extent have become the government's vassal. Of course, Chinese colleges and universities have been given the corresponding administrative level. In particular, with the implementation of the national "211 Project" and "985 Project", administrative tendency has emerged which divide colleges and universities into vice-ministerial level, departmental level and deputy departmental level to manage. Facts have also proved that the effect of the practice which is contrary to the international practice of no administrative level in colleges 
and universities, is counterproductive. It not only has no benefit for the construction of world-class universities and high-level universities, but encourages the "official standard" consciousness, prompts colleges and universities to "run to upgrade to the ministerial level", continuously shows many side effects.

\section{Administrative Level Leads to Administrativization of Colleges and Universities}

As government affiliated institutions, Chinese colleges and universities have very strict organizational procedures. With strict hierarchy, Chinese colleges and universities are just like the top grade bureaucracy. To see it from the appointment of cadres at all levels of the school, the rules are really intriguing. Among them, the rules of university leadership are quite interesting. For the same title of president or secretary, some of them are vice-ministerial level, some are departmental level, others are deputy departmental level, the determination of these levels, are probably extracted from universities level. For the same deputy university leaders, in the vice-ministerial level school, the "executive" is the departmental level, others are deputy departmental level. For some deputy departmental level university leaders, at some point before retiring, when step down from the leadership position, there will be an added bracket indicating the departmental level. There are also some university leaders who are "forced" to retire before reaching the retiring age, being crowned with departmental level or deputy departmental level inspector etc. However, the same level leaders ranking of the present employment in university level is more tangled, because it means greater power with more front rank. Of course, there are rules too. When ranking, in different series of cadres, the party series are in the front; in the same series cadres, people who have an early serving time are ranked in the front. At the same time, there are also people who have a directly specified ranking designated in the appointed file of higher level. However, the setting of internal organization and appointment of cadres of schools are diversified. Set the positions according to certain people, cadre positions are arbitrarily approved; Appoint people by favoritism, the relationship is more important than ability; Intrigue against each other, alienation emerges into the interpersonal relations; Colleges and universities have become a Vanity Fair where academic team does not make efforts to their department and the full team compete for administrative resources. The affiliated institutions directly create a considerable "official team", which is exactly as it describes: there are a corridor of department-level leadership, a hall of division-level leadership, a playground of section-level leadership.

Colleges and universities have the administrative level, naturally, cadres at all levels will have a "level" to be set,, cadres have become corresponding level officials who can enjoy the corresponding treatment such as political status, social reputation, economic income, housing size, car grade etc.. With the rank of the obvious feudal color prevailing in colleges and universities, it has imperceptibly formed "official position" in the mind of school "officials". The "official position" will directly lead to the administerization of colleges and universities. The administration will lead all internal things of school and thus the academic authority will be greatly squeezed which will seriously prevent the implementation of the three major functions of colleges and universities. Therefore, it is the administrative level system of colleges and universities designed by us that create the administrativization of colleges and universities. The administrative level is the "arch-criminal" of administrativization of colleges and universities. Meanwhile, I believe that with the successive promulgation and implementation of Higher Education Law and a series of laws and regulations, 
and the expansion of the autonomy to run colleges and universities, the autonomy of the schools will be abused because the change is still lack of systematicness and standardization as well as self discipline and social supervision, as the phenomenon of "macro-level autonomy expansion eventually cause school's internal micro-level re-centralization, devolution of decision-making authority into schools, however, led to the centralization of power in the 'school executives' "[7] in the process of the expansion of autonomy of colleges and universities in Russia. Moreover, when the society appeals for the necessary reform for the administration of colleges and universities, the university officials are still trying to maintain their own vested interests. During the "Two Conferences " in 2010, a representative of National People's Congress in the field of higher education said that when the whole society were using administrative level as the evaluation criterion, "cancelling the university administrative level will belittle education, resulting in failure of ' butt joint' between university and society ". It is really staggering to use " butt joint " as an excuse to speak out for maintaining administrative level of colleges and universities. It seems that our university officials are never bored with being officials.

\section{The Inundation of Level Complex of Colleges and Universities}

Colleges and universities cannot and should not have administrative levels, but in the meanwhile they are still pursuing other levels, the level complex is inundant. Firstly, the level is determined by scale. It is believed that the bigger area, number of students, and teachers team, the greater the impact of school and the higher level the schools are. Thus, people becomes ambitious and begin to expand wider and wider school area, build more and more exotic schoolhouses, wantonly merge and amalgamate other schools. Disciplines blossom in comprehensive fields. Education level and school type become more and more complex. School scale is getting bigger and bigger and become "Mega-Universities", after that, they strive to be "Super Mega-Universities" and the world's first large-scale university. Secondly, the level is determined by function. It is believed that the research universities are of noble descent and the highest level. However, people sniff at teaching universities. Thus, colleges and universities try their best to keep up with the research universities and get doctoral programs and master's programs which forms a spectacle of research universities striving for "vying". Thirdly, the level is determined by the nature of discipline. It is generally believed that science is more important than techniques. It is considered that occupational colleges are inferior to others and are classified as second-class and receive a cold eye, however, academic colleges are in a high status. Thus, academic colleges and universities are reluctant to run practical and occupational majors, while occupational colleges try every means to get closer to academic colleges. Fourthly, the level is determined by funding sources. It is believed that public colleges and universities are a gold-lettered signboard which guarantee the teaching quality. However, private colleges and universities' teaching quality is barely satisfactory, competitiveness is out of the question. Not to mention whether it is right about the relevant arguments on development scale, function orientation, preference of science and techniques, nature of school, it is not difficult to find just from their persistence on level that colleges and universities indeed have a level complex, and every move is based on a consideration of certain level. In fact, the demand for higher education in the socio-economic development of a country or region is diverse, and different types of higher education take on different social missions. The experience of higher education development in the worldwide tells us that all types of colleges 
and universities can "fame" in their respective fields. The University of Wisconsin which was born in the movement period of American State University, due to opening the function of social service, became the milestone of establishing the third major function of world's colleges and universities. The Massachusetts Institute of Technology is popular all over the world for its high quality of "small but excellent". The transfer education and vocational education in American Community colleges are popular all over the world, etc.

Category and type was irrelevant to level, but wave after wave of government's funding policies on the construction of key colleges and universities contributed to the inundation of level complex in Chinese colleges and universities. Since the founding of New China, colleges and universities have gone through the initial stage of the construction of key colleges and universities and later the construction of the "Project 211" and "Project 985", the "top priority" colleges and universities, however, I think the effect of the "wave style"[8] construction of colleges and universities is unflattering. In particular, the later practice on this basis of linking the categories, types and school administrative levels, undoubtedly played a guiding role in colleges and universities' blind pursuit of the large and the comprehensive, resulting in the prevalence of impetuous and exaggerated vogue in higher education sector. In fact, the actual effect of the government practice is worth implementing which can always make the strong stronger and the weak weaker in colleges and universities. As Clark said, in general, the status of a school is very difficult to change. Long term or short term, it is the strong stronger and the weak weaker. [9]

\section{Colleges and Universities Need Master-level Teachers}

If change the "level" to "reputation" or "fame", or, if the "level" can be actually converted into the real "reputation" or "fame" of colleges and universities, the level will become essential to colleges and universities. But the "level" in this context, means the colleges and universities' "reputation" and "fame". Therefore, if colleges and universities have the real legendary reputation and fame, why won't they have the due level and position in people's mind? After the removal in 1917, Cai Yuanpei was appointed to be the president of Beijing University, but at the time, neither Mr Cai himself nor social, did not think that it was "degraded" or "demoted". Because at that time the status of Peking University in people's minds was supreme. So, what do the reputation and fame of the colleges and universities depend on? The former president of Harvard University, Professor Bock pointed out[10], that "the school's reputation not only mainly depends on the quality of the students, but also mainly depends on the level of teachers." "To make us always in the forefront, in the long run is to have a good professor." Indeed, "Professors are the soul of the University."[11]. To open the history of the University of Gottingen, a world's top mathematician, physicist, chemist and philosopher made it a famous university in the world. Therefore, to win a good reputation and fame, colleges and universities need to have first-class masters, the world-famous master scholars. Without first-class masters, there is no first-class colleges and universities. Harvard University, University of Oxford, Yale University and other schools have a dozen to several dozens of Nobel prize winners, the world's top ten universities have an average of 5 6 Nobel prize winners. In the world's top ten research universities, the proportion of the Nobel prize in 1901-2001 was 39\%, the top 100 accounted for $94 \%$. The first Asian university president in United States professor Tian Changlin, the president of the University of California, Berkeley, when talking about the relationship between masters and universities, pointed out that 
the development of the California Institute of Technology depended on two professors. One was Millikan, winner of the Nobel Prize in physics, who made school experimental physics reach the world class; the other one was Von Karman, the teacher of Mr. Qian Xuesen, who developed the technology of aviation in the United States. With these two people and its own efforts and sustained development, California Institute of Technology has become a world-renowned university. Of course, different types of colleges and universities need different levels of the masters, vocational colleges require masters of technology who are the souls of higher vocational colleges.

During the Anti-Japanese War in China, the Southwest Associated University had no buildings. Schoolhouses were built by adobe in hastily. Classrooms, libraries, laboratories, canteens and dormitories were the same which were almost without any brick house. It was in such a poor education condition that trained the later $\mathrm{Li}$ Zhengdao and Yang Zhenning, two Nobel Prize winners, and Qian Sanqiang, Deng Jiaxian as well as a large number of scientists who made outstanding contributions to the construction of New China. What did it depend on? It depended on the academic freedom system of the university and a group of master-level professors and scholars. The lineup of professors in art college and law college alone, could be described as innumerable. Among which there were Tang Yongtong, Shen Youding, Zhu Ziqing, Wu Mi, Qian Mu, Mao Zhun, Shen Congwen, Feng Youlan, Wen Yiduo and so on, most of them had a thorough knowledge in both Chinese and Western learning, being erudite and informed, were the professional academic authorities in their field. It was because of this, Mei Yiqi, then the president of Southwest Associated University blurted out a famous saying, "Universities are not buildings, but the masters ". Indeed, buildings only represent university material culture, atmosphere represents the system culture of university, however masters represent the spiritual culture of university, and university culture system need spiritual culture to govern, ease, and implement.

\section{Conclusion}

To sum up, there was no administrative level in colleges and universities since the birth, and the administrative level is not necessary to perform all functions. In contrast, administrative level leads to serious administrativeness of colleges and universities. Colleges and universities should not pursue other levels, if you insist that they need administrative level, then what they need most are master- level teachers team.

\section{References}

[1] Yin Qingyan. Continue to Maintain the "Level" is Untenable [N]. Beijing Daily, November 11, 2010 twentieth edition.

[2] Yan Fengqiao. The Organization and Management of Universities [M]. Beijing: Tongxin Press, 2006:66.

[3] Yang Deguang. On the Nature and Function of Modern Universities [J]. Higher Education Research, 2001, (01): 29.

[4] Zhao Tingting. Autonomy, Control and Collaboration - Evolution of Government and University Relations [J]. Modern University Education, 2001, (02): 54.

[5][7] Liu Shuhua. Step into Autonomy of Universities-A Review of the Expansion of Autonomy Reform of the Colleges and Universities in Russia [J]. Comparative 
Education Research, 2009, (06): 36, 40.

[6] Lee Gang. The Origin of the Classification of Higher Education Institutions in China and the Policy Analysis of the Reform and Development of [J].2005, (01): 57.

[8] Zhang Guobing. Research on the Key Construction Policy of Higher Education [M]. Beijing: Peking University Press, 2010:2-3.

[9] Clark. Higher Education System -- the Transnational Research of Academic Organization [M]. Hangzhou: Hangzhou University Press, 1994:218.

[10] Derek Bork. USA Higher Education [M]. Translated by Qiao Jiayi. Beijing: Beijing Normal University Press, 1991:39.

[11] Zhang Chuting. On President of the University [M]. Higher Education Research, 2009, (07): 2 